\title{
O SUJEITO DA EDUCAÇÃO SUPERIOR: SUBJETIVIDADE E CULTURA'
}

\author{
Karina Silva Molon de Souza*
}

\begin{abstract}
RESUMO. Alguns questionamentos acerca do "Sujeito da Educação" nos foram lançados em nosso ciclo de estudos em Educação, destacando-se entre eles: "Quem é o sujeito da educação?" e "As formas de ensinar e aprender modificaram-se, com o tempo?". O presente artigo constituiu-se como uma pesquisa qualitativa do tipo exploratório, enquadrando-se como um levantamento bibliográfico. O estudo mostra que o aluno de hoje não aprende, nem convive ou se relaciona do mesmo modo que no passado. Ele traz os adultos como responsáveis pela organização e significação psicológica da vida dos alunos. Concluiu-se que o questionamento sobre "Quem é o sujeito da educação" parece indispensável para todo educador, e também constatou-se que a definição do espaço de cada um em sala de aula coloca o aluno no centro e o professor como um mediador. Palavras-chave: sujeito, educador, estudante.
\end{abstract}

\section{THE SUBJECT OF UNIVERSITY EDUCATION: SUBJECTIVITY AND CULTURE}

\begin{abstract}
Some questionings about the subject of education in universitary education were launched in our studies cycle in education. Along them, we ask "Who's the subject of education? "; "The ways for teaching and learning have changed if compared to the time past". This paper is a qualitative explorer research, according to a bibliographical rising. My research shows that today's student doesn't learn nor coexist or is connect to others in the same way as he did in the past and it says that adults are responsible for organization and psychological signification of non-adults lives. Concluding, it's possible to say: the questioning about "who is the subject of education" is indispensable for all educator. Today's definition to a space in the classroom sees the student as the core and the teacher as a mediator.
\end{abstract}

Key words: Subject, educator; student.

\section{EL SUJETO DE LA EDUCACIÓN SUPERIOR: SUBJETIVIDAD Y CULTURA}

RESUMEN. Algunos cuestionamientos acerca del Sujeto de la Educación nos fueron lanzados en nuestro ciclo de estudio en Educación. Dentre ellos están: "¿Quién es el sujeto de la educación?"; "¿Las formas de enseñar y aprender cambiaron con el tiempo?". El presente artículo se constituye como una investigación cualitativa del tipo exploratoria, encuadrándose como un levantamiento bibliográfico. El estudio demuestra que el alumno de hoy no aprende, ni convive o se relaciona del mismo modo del que en el pasado. Él trae los adultos como responsables por la organización y significación psicológica de la vida de los alumnos. Como conclusión es posible afirmar que el cuestionamiento sobre "Quién es el sujeto de la educación" parece indispensable para todo educador y también que la definición de un espacio del salón de clase contempla el alumno como el centro y el profesor como un mediador.

Palabras-clave: Sujeto, profesor, alumnos.

O presente artigo foi elaborado com a finalidade de integrar conhecimentos construídos ao longo das discussões no "Seminário Avançado" ofertado pelo Curso de Mestrado em Educação, intitulado "O sujeito da educação no ensino superior", com nossa experiência enquanto alunos no ensino superior. Alguns questionamentos nos foram lançados como forma de incentivo à aprendizagem da presente temática. Entre as indagações estavam questões como: "Quem é o sujeito da educação?", "As formas de ensinar e aprender modificaram-se, com o tempo?", "Hoje se aprende e se ensina de forma distinta daquela em que aprendíamos quando éramos jovens?". "Será que as nossas escolas estão mudando realmente?"

1 Apoio: $\mathrm{CNPq}$.

* Psicóloga. Especialista em Neuropsicologia. Mestranda em Educação na Pontifícia Universidade Católica do Rio Grande do SulPUCRS. Bolsista CNPq. 
$\mathrm{O}$ artigo divide-se em duas partes. Na sessão inicial o destaque é a família, local onde, num primeiro momento, ocorreu a aprendizagem sobre "como ser um educador" e "como comportar-se enquanto educando". A subjetividade, como construção cultural, retrata quem é o sujeito da educação. Mostramos que a mudança nas relações entre pais e filhos trouxe novas formas de ensinar e aprender na universidade. Também enfatizamos que, na história da família, nem sempre a chegada de um filho foi bem-vinda, e que relações de afeto e cuidado surgiram com a finalidade de estabelecer um certo domínio sobre o filho, mediante uma organização social um tanto controladora.

A segunda parte do estudo traz a influência da organização do espaço da sala de aula sobre a pessoa do aluno, seu corpo e sua dimensão psicológica. Mostra também que a visão epistemológica da modernidade deixou marcas na educação escolarizada que podem ser observadas nas escolas atuais, como a disciplinarização dos currículos e a organização escolar e acadêmica. Entre os séculos XVII e XVIII, as monarquias soberanas transformaram-se em sociedades disciplinares, onde o aluno era entendido como aquele que obedecia à ordem da autoridade do professor, que tudo sabia. O capítulo ainda elenca as influências da pedagogia crítica sob a educação opressora e autoritária que vingou até o século XX. Para finalizar esta sessão do artigo, trouxemos uma discussão sobre a prática do professor universitário do século XXI, seus desafios e suas incertezas. Descrevemos, ainda, o aluno no contexto atual e sua relação com a aprendizagem, assim como as modificações na concepção do espaço da sala de aula enquanto lugar de encontro $\mathrm{e}$ de troca de conhecimentos e afetos. Para tanto, foram mesclados relatos de nossa experiência como sujeitos da Educação no Ensino Superior com o referencial teórico, a fim de enriquecer o entendimento do tema.

Enquanto método, o trabalho constitui-se como uma pesquisa qualitativa do tipo exploratório. Conforme Gil (1995) e Richardson e Peres (1989), uma pesquisa exploratória pretende conhecer mais e melhor o problema, elaborar hipóteses, aprimorar idéias e descobrir intuições; além disso, ela pode contar com três modalidades, entre as quais o nosso estudo se enquadra como a de um levantamento bibliográfico.

\section{A FAMÍLIA NA ORIGEM DA CONSTRUÇÃO DA SUBJETIVIDADE DO SUJEITO DA EDUCAÇÃO}

Antes de abordarmos o tema da construção da subjetividade do aluno de forma mais detalhada, faz-se necessário demarcar alguns termos, como sujeito e subjetividade. Ogden (1996, p. 23) traz definições bastante próximas das compartilhadas por nós diante de nossa prática como psicóloga e estudiosa na área de Educação. Para o autor:

[...] o termo sujeito parece particularmente adequado para transmitir a concepção psicanalítica do 'eu' que experiencia tanto num sentido fenomenológico quanto metapsicológico. O termo está etimologicamente legado à palavra subjetividade e mostra uma reflexibilidade semântica inerente, ou seja, denota simultaneamente sujeito e objeto, eu e isso, eu e mim. A palavra sujeito se refere tanto ao 'eu' como quem fala, pensa, escreve, lê, percebe, etc., quanto ao objeto da subjetividade. Assim sendo, o sujeito nunca pode estar totalmente separado do objeto e, portanto, nunca pode estar inteiramente centrado nele mesmo.

A subjetividade é uma construção social. Antes mesmo da concepção, somos investidos psicologicamente por nossos pais. Estes desejos e expectativas que pai e mãe depositam na criança irão unir-se às características biológicas e às influências do meio social mais próximo e amplo, resultando num processo de subjetivação da pessoa. Não é por acaso que psicólogos ou estudiosos da área da psicologia do desenvolvimento procuram um entendimento aprofundado da dinâmica familiar do paciente, através de uma boa entrevista de anamnese com os pais ou cuidadores, se, no caso, o cliente for uma criança.

É na família que, numa primeira instância, a criança é amada e educada. A dimensão familiar, entendida aqui em todas as suas nuanças (nuclear, extensa, social, antropológica, econômica e política), é fundamental para a compreensão da subjetividade humana. O nascimento de um bebê marca a história da união do casal e o nascimento da família, consolidando o "status" adulto dos cônjuges. Relações entre pais e filhos, dentro de um padrão saudável de família, são permeadas de muito afeto e proteção. A criança passa a ser o centro das atenções do casal. Redes de relações se estabelecem em torno dela no bairro, na escola, entre parentes distantes. Uma criança "enche" uma casa de vida, sua espontaneidade extrai risos mesmo de quem não esteja de bom humor.

(...) a criança não é uma abstração-alvo de inquietudes pedagógicas, de exames psicológicos, de ponderações maternas. É objeto não de teorização, mas sim de convivência (...) a jovem noiva pede um 
sobrinho para cuidar até nascer seu próprio filho. As velhas andam a cata de um neto ou uma neta para lhes 'fazer companhia'. Os casais estéreis ficam 'de olho' em algum nenê 'sobrando', isto é, que veio em um momento inoportuno para seus pais (Ariès, 1981, p. 25).

Gimeno (2005) afirma que as relações de cuidado entre pais e filhos intensificaram-se por volta dos séculos XVI e XVII. Para o mesmo autor, os pais passaram a comportar-se de modo mais afetuoso diante dos filhos, garantindo assim o repovoamento do Estado, consolidando a unidade familiar e recuperando os bons costumes. Os filhos, enquanto objeto de desejo dos pais, representam a possibilidade da continuidade de uma propriedade familiar, e ficam sujeitos a atender às expectativas dos cuidadores, numa relação de trocas diante de uma hierarquia de poder. Tudo isso traz implicações no campo da construção da subjetividade da pessoa do filho e da pessoa do aluno. Um sistema patriarcal instituía-se na ordem familiar tradicional, onde a mãe respondia pelo afeto, e o pai, pela ordem. "A importância dada ao laço afetivo de origem maternal supôs uma exigência de qualidade para a pedagogia moderna ao dar ao tratamento acolhedor um valor essencial, que repercutiu no realce da centralidade do sujeito da educação" (Gimeno, 2005, p. 119).

Por outro lado, o modelo paterno autoritário e impositivo não trouxe bons exemplos às práticas de sala de aula, mas a figura do pai como representante do Estado foi muito importante para a construção de uma sociedade organizada. Com a evolução da família e a emergência do Estado liberal, aparecem novas formas de se relacionar com os filhos-alunos. Neste contexto, a Revolução Francesa muda o tipo de dependência que o homem estabelece com o Estado. Agora o Estado garante a segurança dos filhos em relação aos abusos de autoridade dos pais. Pais delegam a função de educar ao Estado e a figura de autoridade se dissolve. A função paterna entra em decadência, interferindo nas relações entre professores e alunos, as quais se tornam menos agressivas ou autoritárias.

Até o final da Idade Média, boa parte da população de crianças não ocupava um lugar de destaque no seio familiar. A educação era confiada a pessoas estranhas ou instituições sociais como reformatórios e casas de caridade. A minoria da população tinha acesso às escolas que ensinavam as primeiras letras. Gimeno (2005) diz que “(...) toda a experiência que temos de trabalhar e tratar os menores, preparada cuidadosamente nas relações de família e em outras situações em que conviver com eles, cuidando, guiando e disciplinando-os, tenderão a ser projetadas na forma de ver e tratar os alunos" ( $p$. 108).

A cultura, quanto ao modo de educar, muda com o tempo, acompanhando o paradigma sociocultural vigente, mas a mudança é lenta, assim como tudo em educação. Marcas ainda persistem em nossos sistemas educacionais, quer implícita quer explicitamente, refletindo-se na avaliação da aprendizagem, que por vezes ocorre de forma unilateral, descontextualizada, autoritária. É a avaliação que favorece a competição entre os alunos, focada na nota, nos desempenhos, nas habilidades cognitivas.

Neste sentido, podemos citar nossa experiência relacionada à avaliação enquanto sujeitos da educação superior, no curso de Psicologia ao longo dos anos de 2001 e 2005. As metodologias de ensino eram variadas. Éramos submetidos a provas, trabalhos em grupo, seminários reflexivos. Terríveis eram as provas objetivas, fechadas. Protestávamos, escrevíamos ao lado das afirmativas, acrescentávamos reticências, pontos de exclamação, coloríamos. Mas, ao longo do tempo, mudanças ocorreram, principalmente nas disciplinas mais voltadas para a prática do psicólogo clínico, hospitalar ou institucional, e já apareciam timidamente provas subjetivas, mais flexíveis. Nós, alunos, reagíamos, é claro. O nível de exigência era maior, demorávamos mais, dissertávamos longas páginas. Ao findar o trabalho, o sentimento traduzia-se por exaustão. Os professores passaram a admirar os resultados, nós, alunos, igualmente. Por outro lado, continuávamos presos à avaliação, à medida. Questiono-me: “As nossas escolas estão mudando realmente?", “A minha escola assemelha-se à sua?”.

Tendo-se em vista o que foi citado acima acerca de nossa vivência como aluno, é interessante ressaltar dois aspectos: a autonomia do aluno e a relação entre professor e aluno. A autonomia, porque nos comportávamos como verdadeiros agentes de nossa aprendizagem, mostrando nossa insatisfação, indagando, investigando, criticando. Encontramos espaço para o diálogo, um dos saberes necessários à prática educativo-crítica elencados por Freire (1996). Nossos professores, em sua maioria, estavam dispostos a conversar, demonstrando preocupação com nosso descontentamento. Prevalecia, em sala de aula, um clima de aceitação e afetividade. Segundo Rogers (1992), a abordagem educacional que coloca o aluno como centro do processo permite o exercício da autonomia, na gestão e no controle da aprendizagem.

Corroborando essas asserções, Pozo (2006), ao referir-se às mudanças impostas ao sistema 
educacional, diz que alguns aspectos, como as relações entre professores e alunos, assim como as formas de falar e se comportar, modificam-se mais rapidamente se comparados com os conteúdos do ensino, as tarefas escolares e os sistemas de avaliação. Destarte, as mudanças no campo da educação, no que se refere às relações interpessoais e ao modo de ensinar os conteúdos e avaliar, são muito lentas e em algumas ocasiões podem ser mais visíveis num plano conceitual do que no dia-a-dia das salas de aula.

$\mathrm{Na}$ atualidade a percepção do adulto com relação ao aluno parece estar desajustada. $\mathrm{O}$ aluno de hoje não aprende nem convive ou se relaciona com o professor do mesmo modo que no passado. Este estranhamento teve início no final do século $\mathrm{XX}$, quando ocorreu uma mudança estrutural nas instituições educacionais, a qual trouxe consigo uma nova forma de relação entre as pessoas e conhecimento.

No período que precedeu o século $\mathrm{XX}$, as relações familiares tomaram uma nova direção. A definição sobre quem é o sujeito da educação parecia ainda mais complexa. Em conseqüência disso, as relações entre alunos e professores alteraram-se. $\mathrm{O}$ aluno iria identificar-se projetivamente com o professor e tenderia a comportar-se no espaço da sala de aula de modo semelhante à forma como se relaciona com os pais. Outras vezes ele pode opor-se aos modelos familiares, numa tentativa de transgredir as normas, diferenciar-se destas relações, porque os modelos passam a ser percebidos pelo filho como "alienantes". Esse modo de agir perante o professor irá depender de uma gama de fatores, como a subjetividade do aluno, a fase do ciclo vital em que se encontra e, fundamentalmente, a cultura e aspectos situacionais bem específicos.

Para ilustrar a afirmação acima, cito minha experiência como sujeito da Educação na graduação em Psicologia. Em determinadas situações de sala de aula eu sentia certo desconforto quando me deparava com atividades flexíveis que permitiam livre escolha, como, por exemplo, a formatação de um trabalho no início do curso, que não seguia um modelo ou normas técnicas específicas. Para mim, isso era desagradável. Um padrão familiar rígido e autoritário pode favorecer o desenvolvimento de subjetividades muito exigentes, dependentes ou inseguras. Podemos dizer: a vivência de ser aluno é singular (a minha também), assim como a experiência de ser filho. A análise pormenorizada destes modos de ser e estar, nos diferentes contextos educacionais (família, escola, universidade) pode trazer informações valiosas sobre quem é o sujeito da educação.

\section{A SALA DE AULA MODERNA: QUEM É O SUJEITO DA EDUCAÇÃ O?}

Num passado pouco distante, as crenças religiosas e o senso comum eram as únicas fontes de conhecimento legítimo para interpretar o mundo. A observação da natureza trazia uma compreensão precisa acerca do universo e as interpretações subjetivas eram válidas até que se provasse o contrário. Foi a modernidade que rompeu com o estado feudal e com estas formas obscurantistas de entender o mundo e a relação do homem com a natureza. Para que um conhecimento seja válido, no mundo moderno, é preciso ser comprovado cientificamente por meio de um método científico. Corroborando isso, Cunha (2005) afirma que a visão epistemológica da modernidade deixou marcas na educação escolarizada que podem ser observadas nas escolas atuais. Entre estas marcas estão a disciplinarização dos currículos e a organização escolar e acadêmica.

A disciplinarização do currículo e a organização escolar e acadêmica trazem consigo determinações sobre a definição de um sujeito da educação moderna. A construção do conhecimento científico exigia a separação entre corpo e mente, sujeito e objeto, teoria e prática, ciências exatas e ciências sociais e humanas. No presente cenário, corpos docilizam-se, dominamse, conduzem-se. Isso ocorre a partir dos séculos XVII e XVIII, quando o poder da soberania é substituído pelo poder disciplinar. As monarquias soberanas transformam-se em sociedades disciplinares. As sociedades disciplinares tiveram seu auge no século XX. Aluno, neste contexto, é aquele que obedece à ordem da autoridade do professor, que tudo sabe.

Professor e aluno no mundo moderno, industrializado, submetem-se ao paradigma educacional racional ou tecnosistêmico. O educando submete-se às expectativas e diretivas do educador, ou seja, recebe a mensagem predeterminada e domina as suas emoções, sua imaginação, sua sensibilidade, sua afetividade. Aluno é um sujeito receptivo, passivo. Assiste às aulas e responde adequadamente, ou melhor, responde o que professor deseja ouvir. E o resultado da avaliação deve corresponder a um modelo de aluno ideal. Ela segue um modelo normativo e idêntico para todos os alunos.

Ainda com relação ao paradigma educacional racional, é interessante dizer que a abordagem pedagógica mais coerente com ele é a mecanicista, em que conhecimentos e valores são transmitidos, a avaliação do comportamento ocorre por comparação e, por fim, o professor domina, motiva e dirige os alunos. O conteúdo da comunicação centra-se nas atividades 
cognitivas. O professor é entendido como o centro do processo. Conforme Bertrand e Valois (1994), a abordagem mecanicista marcou a educação contemporânea tendo como objetivo manter a tradição cultural ocidental, uma vez que toda abordagem pedagógica carrega consigo um tipo de sociedade que busca atualizar, e também, num nível micro, a abordagem pedagógica atualiza o tipo de profissional que pretende lançar no mercado de trabalho.

Entender a constituição da subjetividade do sujeito da educação também perpassa por determinadas peculiaridade da carreira. Isso quer dizer que a formação do médico ou do químico difere da formação do psicólogo e do sociólogo, ou seja, o modo de se relacionar com o conhecimento e com os docentes toma formas diferentes para amoldar-se às áreas de trabalho.

Deste modo, podemos pensar que professores de pedagogia deveriam ser os precursores de uma pedagogia nova, oposta ao paradigma racional ou tecnicista. Avançando um pouco mais, as características e, talvez, os esteriótipos das profissões nem sempre são fontes fidedignas, porque esteriótipos são generalizações simplificadas e também a formação do aluno/profissional não depende unicamente desses modelos. Portanto, a formação do sujeito da educação, suas relações com o conhecimento e com a pessoa do professor perpassam por peculiaridades referentes às carreiras que a universidade oferece (por exemplo, o modo como o docente concebe o conhecimento e como ele percebe a pessoa do aluno enquanto um profissional incluído no mercado de trabalho) e a formação do sujeito da educação sofre interferência do projeto de vida pessoal e profissional que o aluno vem construindo ao longo da escolarização.

Embora saibamos que os princípios do paradigma da racionalidade não condizem mais com uma sociedade em mudança como a nossa, observamos resquícios deste nas escolas e universidade de hoje. A emergência do paradigma industrial trouxe a crença num progresso pessoal e material e a promessa de felicidade para todos. Embora o paradigma tenha cumprido a promessa do desenvolvimento, não trouxe mais alegria e paz à população. As desigualdades sociais cresceram enormemente, o desenvolvimento tecnológico aumentou a competição entre as nações, a exploração e o domínio da natureza prejudicaram a saúde do homem, as oportunidades de emprego diminuíram, o individualismo e o materialismo vieram à tona. A pedagogia entendia o aluno como matéria moldável.

Para Foucault (2002), o poder não somente reprime, mas também produz efeitos de verdade e saber, constituindo práticas e subjetividades. Foucault (2002) compara a escola a um observatório político, um aparelho que permite o controle perpétuo da população através da burocracia escolar. O poder é como uma rede, onde o homem é objeto e sujeito das práticas de poder. No século XVIII, a criança é enviada à escola principalmente para aprender a obedecer a ordens, não contestando o sistema político e social vigente. $\mathrm{Na}$ verdade, a escola era um local onde toda a espontaneidade e criatividade da criança era tolhida, corpos eram docilizados, moralizados, controlados.

Como no convento, no internato ou no quartel, embora podemos sair e entrar com mais facilidade, no espaço e no tempo escolares as possibilidades da vida dos sujeitos ficam cercadas e limitadas (...) Cada atividade (recreio, estudo, descanço) e cada tarefa acadêmica (prestar atenção na fala do professor, ler, escrever, resumir (...) representam formas de utilizar o espaço e o tempo (Gimeno, 1988, p. 143).

$\mathrm{Na}$ Universidade, as formas de utilizar o espaço e o tempo também “dizem” alguma coisa sobre as formas de se relacionar. Lembro-me da minha experiência enquanto sujeito da educação no Ensino Superior, a começar pela distribuição das classes, que eram organizadas em fileiras rigidamente dispostas. Na sala havia quadro-negro, giz e retroprojetor. O prédio era dividido em três andares. A sala de professores localizava-se no primeiro andar, num corredor bem ao fundo, onde estava um homem robusto e sério "cuidando" da entrada e saída de pessoas. Não é preciso mencionar quanto era dificultado o acesso dos alunos aos professores. Os primeiros três anos na graduação foram marcados por aulas expositivas e pouco dialogadas.O aluno escutava com olhar atento, procurava não distrair-se com estímulos externos e evitava ir ao banheiro fora de horário (horário de banheiro é no intervalo). $\mathrm{O}$ professor não diversificava muito as metodologias de ensino. Determinadas "inovações" causavam impactos, nem sempre positivos.

Foi a pedagogia crítica que se movimentou para "salvar" o aluno da submissão, do autoritarismo familiar, da repressão e da manipulação de sua consciência, até então cultivados pela escola. O movimento da Escola Nova assumiu algumas das teses de Dewey e Paulo Freire. A partir dessa ocasião, o aluno é visto como sujeito da educação, e ocorreu ainda a valorização da autoformação e da atividade espontânea da criança. O dever da educação passa a ser, segundo Gadotti (1995), conservar e aumentar o impulso vital e espiritual do aluno. O aluno passa a ser visto como autor de sua própria experiência, como centro do processo de aprendizagem. O movimento 
escolanovista foi mal interpretado pelos educadores, porque alguns se omitiram em delimitar a ordem no espaço da sala de aula. A liberdade e autonomia foi confundida com libertinagem, assim como a autoridade está para o autoritarismo. De qualquer maneira, o aluno estava inserido numa sociedade burguesa e a Escola Nova acompanhou o desenvolvimento e o progresso do capitalismo. Aluno era quem aprendia um ofício, preparando-se para o exercício da competição.

O século XXI marca a entrada num novo mundo. Homem e natureza gritam por socorro. Os sistemas educacionais mostram-se cientes da crise epistemológica moderna, mas também estão confusos quanto à atitude a ser tomada, porque a mudança não ocorre de uma hora para outra, é processual. A mudança mexe com aspectos da constituição da docência que é enraizada na subjetividade do professor, preenchida pela vivência educacional deste como filho e posteriormente na condição de aluno. "O aluno, como a criança, o menor ou a infância, em geral, são invenções dos adultos, categorias que construímos com discursos que se relacionam com as práticas de estar e de trabalhar com eles" (Gimeno, 2005, p. 13).

Ainda no cenário do Ensino Superior, fomos vivenciando alguns acontecimentos que nos marcaram. Parece que gradativamente o ensino foi se deslocando da abordagem instrucionista de reprodução para a construtivista de relação. Fileiras de carteiras foram desfeitas, a cópia foi substituída pelo diálogo, a prova objetiva pela dissertativa, enfim o palco e os atores não eram os mesmos. A partir disso, Zabalza (2004) diz que um dos grandes desafios da formação dos professores universitários está em unir ensino e aprendizagem. Para isso, o professor necessita trabalhar novas estratégias de ensino na sala de aula, de modo a "tatear" as formas pelas quais o aluno aprende, refletir sobre sua prática tendo em vista a avaliação dos alunos, e transformar o aprender num processo contínuo.

Aos poucos, o professor passa a ter novos olhares sobre o ensino e a aprendizagem. Estes "olhares" se refletem sobre a pessoa do aluno. A mim, particularmente, atingiram positivamente. A autonomia foi incentivada ou reforçada. Os estágios nos mostravam as direções, interesses, preferências por áreas de estudos. Parecia que os caminhos estavam sendo traçados, a aprendizagem facilitando-se ao mesmo tempo em que nos sentíamos incompletos, inacabados, como verdadeiros aprendentes. A citação abaixo retrata uma parte de mim. Faço das palavras de Moran (2001) as minhas:

Aprendemos realmente quando conseguimos realmente transformar nossa vida em um processo permanente, paciente, confiante e afetuoso de aprendizagem. Processo permanente, porque nunca acaba. Paciente, porque os resultados nem sempre aparecem imediatamente e sempre se modificam. Confiante, porque aprendemos mais se temos uma atitude confiante, positiva, diante da vida, do mundo e de nós mesmos. Processo afetuoso, impregnado de carinho, de ternura, de compreensão, porque nos faz avançar muito mais (Moran, 2001, p.24).

Afinal, quem é o sujeito da educação de hoje? Ele é sujeito e objeto da educação. Os papéis sociais de professor e de aluno assumem novo caráter, numa relação simétrica, de partilha, de trocas. As informações extrapolam o discurso do professor e do material didático, as fronteiras entre as disciplinas cruzam-se, entrelaçando saberes, extrapolando a racionalidade técnica e o conhecimento prescrito. $\mathrm{O}$ aluno é ativo, porque aprende melhor quando vivencia, estabelece vínculos e laços (integrando as informações); ele aprende bem quando tem interesse e motivação clara, quando desenvolve hábitos que facilitam o processo de aprendizagem, quando sente prazer no estudo e integra as dimensões emocional, pessoal e social.

A sala de aula moderna é lugar de encontro, de troca de experiências, de construção e reconstrução do conhecimento. Relações de ensinar e aprender complexificam-se a cada dia, diante das exigências do mercado de trabalho e dos desafios colocados por uma sociedade globalizada. Pozo et al. (2006) colocam que os sistemas educativos "(...) estão submetidos a uma contínua exigência de mudança (...) É a reforma que não acaba e que, como veremos, afeta não só a organização dos conteúdos, mas cada vez mais a uma mudança nas formas de ensinar e aprender, em resumo, na gestão do conhecimento" (Pozo et al, 2006, p.29). Reconfiguram-se papéis atribuídos ao professor e aos alunos. Conforme Cunha (2005), responsabilidades e autorias são partilhadas, ocorre o "alargamento do conceito de sala de aula, que precisa explodir as linhas retas do espaço retangular que dimensiona e inclui o movimento e a possibilidade de novas racionalidades" (Cunha, 2005, p. 77).

\section{ALGUMAS CONSIDERAÇÕES}

A construção de uma concepção acerca do sujeito da educação perpassa pelo entendimento da relação deste com seu primeiro núcleo de socialização: a família. É na família que se inicia o longo processo de subjetivação do homem. A subjetividade é uma construção cultural que muda com o tempo. Sendo 
assim, o homem do século XXI não é o mesmo da Idade Média. A família de hoje retrata um novo filho, e em conseqüência disso, surge outro perfil de aluno.

A disciplinarização dos currículos e a organização escolar e acadêmica trouxeram uma visão específica de sujeito da educação. Entre os séculos XVII, XVIII e XIX predominou o poder disciplinar, e o aluno, neste cenário, foi aquele que obedeceu à ordem da autoridade do professor, poder absoluto. Foi a pedagogia crítica, a partir do movimento da Escola Nova, que se ocupou de libertar o aluno da submissão, do autoritarismo familiar, da repressão e da manipulação de sua consciência. A partir do século XX, período de desenvolvimento econômico e social marcado pelas características de uma típica sociedade burguesa, o aluno passou a caracterizar-se como quem aprende um ofício, preparando-se para o exercício da competição. Já o século XXI marca a entrada num novo mundo, em que professor e aluno desempenharam papéis cada vez mais complexos, formando um ambiente com duas gerações em diálogo.

Como afirma Gimeno (2005), são os adultos que, como seres mais capazes, organizam e significam psicologicamente a vida dos não-adultos, futuros adultosalunos. Destarte, ser professor do ensino superior, no sentido pleno do termo, requer algumas habilidades, como a capacidade de construir um espaço amoroso e não competitivo, bom de viver; um ambiente alegre e saudável para todos os educandos, onde seja possível contar com o outro para compartir as dificuldades do diaa-dia em clima de compreensão e respeito.

O questionamento sobre "Quem é o sujeito da educação" nos parece indispensável para todo educador. Pensar sobre a nossa vivência em tempos passados com nossos "mestres" e reportar a reflexão à prática com nossos queridos alunos pode ser uma grande proposta de inovação em educação. Hoje a definição de um espaço de sala de aula contempla o aluno como o centro e o professor como um mediador; no entanto, o desafio encontra-se exatamente neste ponto de deslocamento: deslocamento de um extremo ao outro, do professor ao aluno como centro.

(...) bastaria dizer que cabe ao professor renunciar a um modelo determinado por ele próprio, aceitar o modelo que lhe confere o aluno, suportar a importância daí emanada e conduzir seu aluno em direção à superação dessa importância; eclipsar-se para permitir que esse aluno siga seu curso, assim como o fizeram os pais desse aluno (Kupfer, 1989, p. 93).
Não obstante, a conquista da autonomia do sujeito da educação não é uma tarefa fácil! Faz-se urgente maior investimento governamental e motivação por parte do docente em formação continuada e a construção, no contexto das escolas e universidades, de espaços propícios para reflexão sobre a prática cotidiana. O desenvolvimento da subjetividade do sujeito da educação está relacionado com a qualidade do ensino, isso quer dizer que a autonomia do aluno depende de um movimento de reforma educacional que vislumbre a formação humanística do cidadão.

\section{REFERÊNCIAS}

Ariès, P. (1981). História social da criança e da família. Rio de Janeiro: Zahar.

Bertrand, Y., \& Valois, P. (1994). Paradigmas Educacionais: escola e sociedade. Lisboa: Instituto Piaget.

Cunha, M. I. (2005). Sala de aula: espaço de inovações e formação docente. Em: D. Enricone, \& M. Grillo (Orgs.), Educação Superior: vivências e visão de mundo (pp. 71-82). Porto Alegre: EDIPUCRS.

Foucault, M. (2002). Vigiar e Punir. Nascimento da prisão (26 ed.). (R. Ramalhete, Trad.). Petrópolis: Vozes.

Freire, P. (1996). Pedagogia da autonomia - saberes necessário à prática educativa ( $30^{\mathrm{a}}$ ed.). São Paulo: Paz e Terra.

Gadotti, M. (1995). História das idéias pedagógicas ( $8^{\mathrm{a}}$ ed.) São Paulo: Ática.

Gil, A. C. (1995). Como elaborar projetos de pesquisa (4. ed.) São Paulo: Atlas.

Gimeno, S. J. (2005). O aluno como invenção. Porto Alegre: Artmed.

Kupfer, M. C. (1989). Freud e a educação. São Paulo: Scipione.

Moran, J. M. (2001). Ensino e aprendizagem inovadores com tecnologias audiovisuais e telemáticas. Em J. M. Moran, M. T. Masetto, \& M. A. Behrens (Orgs.), Novas tecnologias e mediação pedagógica ( $3^{\mathrm{a}}$ ed., pp. 137-144). Campinas: Papirus.

Ogden, T. (1996). Os sujeitos da psicanálise. São Paulo: Casa do Psicólogo.

Pozo, J. I. (2006). Nuevas formas de pensar la ensenanza y la aprendizaje: Las concepciones de profesores y alumnos. Barcelona: GRAO.

Richardson, R., Peres, J. (1989). Pesquisa social: métodos e técnicas: métodos e técnicas ( $2^{\mathrm{a}}$ ed.). São Paulo: Atlas

Rogers, C. R. (1992). Terapia centrada no cliente. São Paulo: Martins Fontes.

Zabalza, M. A. (2004). O ensino universitário: seu cenário e seus protagonistas. Porto Alegre: Artmed.

Recebido em 27/07/2007 Aceito em 17/05/2008
Endereço para correspondência :
Karina Silva Molon de Souza. Rua: Silva Jardim, 2386, ap. 02, Bairro Centro, CEP 97050700, Santa Maria-RS, Brasil.E-mail: ksmolon@gmail.com 